\title{
11. The Single Shot, Narration, and Creativity in the Space of Everyday Communication
}

\author{
Roger Odin
}

One of the most surprising developments in the recent evolution of cinema is the inscription of filmic language as an operator in the space of everyday communication. The space of everyday communication refers to interactions with communicative intent between ordinary people (including with oneself) about the ordinary affairs of everyday life. What is of interest here is when filmic language is used to communicate common interests, what happens when nothing is happening or, according to Georges Perec, "what happens every day, and comes around every day, the banal, the everyday, the obvious, the ordinary, the ultra-ordinary, the underlying noise, the habitual" $(1975,253)$.

It immediately becomes clear that in this field, the single shot is paramount. To say that in this context there is hardly time or opportunity to edit seems inadequate as an explanation. It seems truer to recognize that the situation puts me in a position where making anything other than a single shot would seem inappropriate. In ordinary spaces, the simple idea of cutting a shot to change the angle is problematic. It is a matter of positioning: the person who is filming feels the obligation to take responsibility for the spatial and temporal continuity of the event being showcased, since he or she belongs to this space and is conscious of the fact that he or she belongs to it. Here Bazin's rule of "montage forbidden" finds its most appropriate application: "when what is essential to an event depends on the simultaneous presence of two or more aspects of the action, montage is forbidden" (1969, 127). This is exactly what happens in such cases. The person who is filming forms part of the system of relations. Therefore, there is great temptation to believe that we are seeing a return to the language of early cinema, a victory of "monstration" over narration. It seems to me that this way of describing the situation does not address what is really happening: in particular, it neglects the fact that those who create such shots have integrated (at least implicitly) the figures of filmic language, and the fact that cinema always has to do with narrativity (though not necessarily with storytelling) (Odin 2000, chap. 2). Nowadays, we can no longer film naively. 


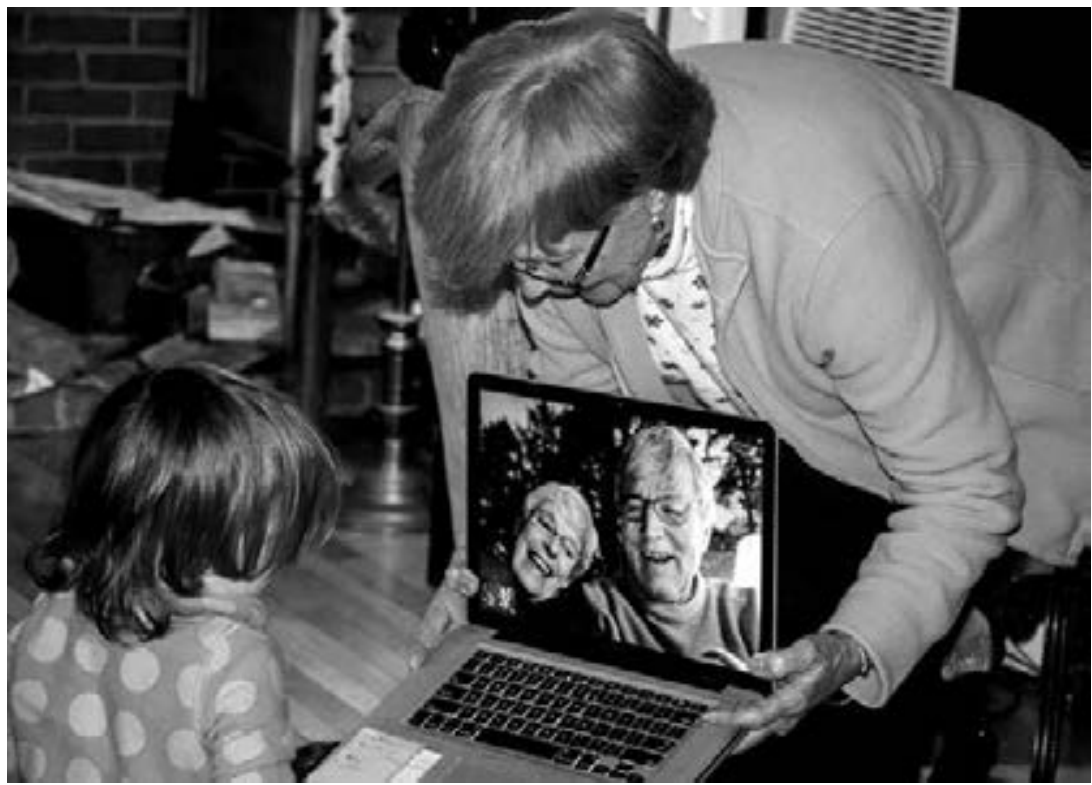

Fig. 11.1: Visiting grandparents by Skype.

Consider the following example: the classic scene of grandchildren visiting their grandmother. Using his smartphone, the grandson films the welcoming at the door and the embraces between people, moving closer to catch the words of welcome and polite greetings; then, without cutting, he enters the house and tracks the visitors into the living room; and still without cutting, he pans around the room before finishing with a close-up of a black-and-white family photograph on the wall. What we have here is clearly a mini-story and, more precisely, a sequence shot, complete with internal montage and complex camera movements.

More examples follow below. A man films himself while walking in a bumpy tracking shot. We experience the creative work of the cameraman as we see the close-up of his face, his eyes narrowed as he concentrates on the movements necessary to keep himself in the shot. At the same time, we discover the space in which he is walking, that is, the vast commercial centre of an Asian city. We cannot say this is a case of description; in fact, the shot makes us participate in the man's discovery of the space in which he is walking: this is clearly a case of first-person narration. Then, a couple is waltzing and filming themselves from above; the man holding the stick is watching it, while the woman watches him. The effect produced makes us lose our spatial bearings, and leads us to wonder: Will the man who is filming end up looking at his partner (which is indeed what happens)? The question 
arises from a narrative reading of the shot by the spectator (who asks the question). The main difference between a selfie still (monstrative) and a video is that in the latter, a process of narrativization is often introduced. In The Aesthetic Life, Laurent Jenny writes:

How often my eye is caught by the picturesque display of one of those New York grocery shops run by Pakistanis that stay open day and night, offering a heterogeneous panorama of goods, ranging from biros to bouquets of flowers [...] mechanically, I take out my mobile phone ... and in order to see more, I find myself using the digital zoom to compare the effects of transparency between ice cubes and banana. Checking the result fills me with amazement. The subject has become totally unrecognizable, having turned into an undeniably cubist composition, from that marvelous period between 1908-12 [sic], when Braque and Picasso were teetering on the edge of abstraction. [...] The whole gives the impression that forms and colors have been crushed into a frame that contains them with difficulty and from which they want to escape. (2013, 89-91)

Here we are definitely discussing a special form of monstration which aims at the transformation of a trivial filmed object into an abstract artistic production. The monstration is narrativized by the impetus of the subject of enunciation (what Ricoeur [1984, 88-89] calls a "phrase of action": the formula is " $\mathrm{X}$ does $\mathrm{A}$, with such an aim, in such and such circumstances, etc."). It is also important to note, however, that the pleasure of passing into abstraction is henceforth shared by a large number of people. Feeling somewhat disillusioned, Jenny notes that "What was once refined aesthetic practice has become a kind of democratic habitus" $(2013,69)$.

Another remarkable form of recourse to the single shot in ordinary space is provided by GIFS or Vines which create a "loop" effect. ${ }^{2}$ Here it may seem that we have returned to the precinema era of the Zoetrope, the Praxinoscope, or the Kinetoscope, as Lev Manovich has suggested (2001, 264-268). However, the novelty is that everyone can produce these loops by using a simple application. Transformation is very clearly at the heart of these productions. It is not always narrative and can be confined to a repetitive movement (the play of light on a woman's face; a colored carousel rotating in the night like a magic ring), but when it is, the effect is a triumph of surprise. The shift between the action shown and the loop effect (a fall from a skateboard which has been looped produces a guaranteed comic effect); the wait for a transformation that never comes, as when a glass is constantly filled with wine but the level never rises; or the deceptive wait, when a magician taps 
his finger on the ace of hearts and we wait for the card to change but it turns out to be the magician who has changed into a large black man while the card stays the same. Of course, we find constructions such as these in early cinema. However, at that time, they were discoveries. Today, making a GIF or a Vine is one choice among many (as one might decide to create a haiku in poetry). We are now dealing with a genre.

Finally, it must be acknowledged that many of these shots exist only in the moment in which they are created: they are not recorded. Filmic language may be involved, but this is direct or live communication, as in some television programs. It might begin with a Skype call between a young couple and grandparents who are abroad. After a moment, the young man's voice says, "I'm going to show you something," and then, without any cut, the mobile phone is turned toward a television screen in the living room, on which appears a video showing a young child taking its first steps. The voice of one of the grandparents is heard, asking, "Are those his first steps?"; then the grandfather says that he is sorry that he cannot speak to Laleh, who is not there. Following this, another young woman calls Laleh on her mobile, and the grandparents are able to see her on the mobile of the young woman who is in contact via Skype, and who films her husband's mobile ... An Iranian student described this situation to me, which was a common occurrence in her family. In this case, narration passes through a combination of different devices; and it really seems to be a new way of telling or showing. In addition, it is also found elsewhere, outside everyday space, for instance in art installations, transmedia storytelling, and business communications.

Such shots are a sign of real inventiveness. More generally, according to D.W. Winnicott ([1970] 1986), they are a sign of our ability to "live creatively," retaining throughout our lives something which belongs to the earliest experiences of childhood: the feeling of being able to create a world. Subsequently, we could speak of transitional creativity. ${ }^{3}$ It is enough to look at what people do to realize that there is a certain joy in the way the single continuous shot engages with/captures everyday life.

\section{Translated by Ian Christie}




\section{Notes}

1. On the difference between "monstration" - literally "showing" - and narration, see Gaudreault (1987). (translator's note).

2. Vine was a short-form video hosting service which users could use to share six-second-long looping video clips. The service was founded in June 2012, and acquired by Twitter in the same year, just before its official launch. GIF, or Graphics Interchange Format, is a bitmap image format introduced in 1987 , especially suited to short animations.

3. In 1953, Winnicott introduced the term "transitional object" to describe those blankets, soft toys, and bits of cloth to which young children frequently develop intense, persistent attachments. He believed that such attachments represent an essential phase of ego development leading to the establishment of a sense of self. See Winnicott's seminal work, Playing and Reality (1971).

\section{References and Further Reading}

Bazin André. 1969. "Montage interdit." In Qu'est-ce-que le cinéma? Ontologie et langage. Paris: Cerf. Gaudreault, André. 1987. "Narration and Monstration in the Cinema." Journal of Film and Video 39, no. 2 (Spring): 29-36.

Jenny, Laurent. 2013. La vie esthétique: Stases et flux. Lagrasse: Verdier. Manovich, Lev. 2001. The Language of New Media. Cambridge, MA: MIT Press.

Odin, Roger. 2000. De la fiction. Brussels: De Boeck.

Perec, Georges. 1975. “Approche de quoi." In Le pourrissement des sociétés, edited by Paul Virilio, 251-255. Paris: Union générale d'éditions. https://remue.net/cont/perecinfraord.html. Ricœur, Paul. 1984. Temps et récit, II. La configuration dans le récit de fiction. Paris: Seuil. Winnicott, D.W. 1971. Playing and Reality. London and New York: Routledge.

—. 1986 [1970]. "Living Creatively." In Home Is Where We Start From, edited by Claire Winnicott, Ray Sheperd, and Madeleine Davis, 39-54. New York: W.W. Norton. 
